\title{
Hong Kong (short films)
}

By Loh, Shih Chiu and Toh, Hai Leong

Spring 2000 Issue of KINEMA

\section{COMING-OF-AGE OF HONG KONG'S INDEPENDENT SHORT FILMS}

An interesting phenomenon as a result of Hong Kong's handover to China in 1997 was a profusion of innovative short films by young directors who worked mostly in video. Their "shoot-on-the-run" films, made on shoestring budgets, documented the anxieties and opinions of the ordinary Hong Konger about the colony's return to the mainland.

Ten of these shorts, ranging from 5 to 30 minutes, were shown at the $22^{\text {nd }}$ Hong Kong International Film Festival (HKIFF) in 1998 under the title 'Digital Biography of Hong Kong, Progams I \& II'. The 'digital diaries', as these videos were called, were commissioned by the Japanese producer Mio Hani and Stella Sze.

Program I offered Howard Cheng's fragmented, two-part, experimental video, The Daily Mood of Final Certainty or The House of August, about 5 characters. Leung Ping-kwan's Moving House: Why Do I Always Forget to Turn On the Camcorder At Crucial Moments was an amusing, absurdist vision of a fumbling video chronicler in London and China. Lew Kwai-cheung's Hands Over Belly Button, in which the director used the belly-button to comment on the 1997 Reunification, was obscure to say the least.

More straightforward was the 30-minute video, Fuss Fuss 1997, by directors Zunzi and Chen Ya, a collection of off-the-cuff interviews with the man-in-the-street, using a jerky hand-held camera in the style of Lars von Trier. The video recorded a mish-mash of opinions, from the serious and scholarly to the sarcastic and droll. Chun Shun's 97 Tons of Memories was an ambivalent, 13-min short about forgetting.

In the more substantial Program II, pro-democracy politician Christine Loh captured the transience of life in her lyrical 6-minute short Hello, Goodbye where the familiar greetings served as an allegory of Hong Kong's departure from Britain and return to China. Balancing Loh's witty lyricism was fashion designer, William Tang's Pun Choy (Big Pot Food). The film intercut a fashion show with the preparation of pun choy to the soundtrack of P.K. Leung's cheeky chant about 1997. Yank Wong's 37-min People In Searching/1997, was a road video that discoursed on the symbolisms of 1997, revealing in the process, a subtext of uncertainty, indifference, doubt, hedonism and identity. Fan Yuk Man's I Am 17 was a simple record of images of the filmmaker and those around him in 1997.

A milestone for Hong Kong short films took place in 1999 when the $23^{\text {rd }}$ HKIFF included the winners of the1998 Independent Film and Video Festival (IFVA) in its programme. This enlightened move proved that indigenous shorts had gained official recognition, in spite of their non-mainstream nature. Many of these videos pushed the limits of story-telling in fictionalised accounts or documentaries while others were passionate statements of life in post-1997 Hong Kong.

Among the works seen was Yank Wong's Kong-O-Ma-Tau, shot on the eve of Macau's reunification with China. Others that stood out included Reeve Tang and Sidney Kwok's graduation film, In March, a romance between a teenager from Hong Kong and a girl from Shanghai. The couple seems to reflect a hopeful Hong Kong-China relationship but the conclusion has them cycling towards an uncertain future. Another interesting work was George Cheng's allegorical 16-mm premiere, Red, Black and White in which a man rises to dance while asleep. Chu Hung Kwan's unusual Apple of Sodom (5 min, VHS) won a Distinguished Award in the Music Video Category in 1998. This dark and melancholic computer anime contemplates the state of modern youth set to the eerie music of Marilyn Manson. Rita Hui's Silver Award winner, The Invisible City (Wall) has collage-like images in a mix of Mandarin and Cantonese, hinting at the wider issues of communication, identity and memory. Hui's video is a fitting discourse on the symbolic power of language as Cantonese gives way to Mandarin in post-1997 Hong Kong.

At 60 minutes, Lo Hoi Ying's video, Hong Kong Guy, is a tale about a bored youth who returns from a trip abroad and mysteriously finds his home occupied and his parents and friends missing and sets out to China 
to find them. The film's reference to China and its themes of anxiety, escape, fantasy, nostalgia, longing and identity, evident in recent shorts, show that Hong Kong's filmmakers are still coming to terms with the island's return to China.

Without resolving their complexes of anxiety and helplessness, it is clear that Hong Kong's independent short films have matured artistically, fuelled not only by the historical changes of 1997 but also by the technological advances in digital video. This medium, much cheaper and therefore more accessible to fledgling filmmakers, has already started to replace the celluloid film of the past as far as short films are concerned. 